\title{
Anne Marie Miraglia, Les figures du père immigré dans le texte dit «beur», «Francofonia»
}

\section{Dina Catenaro Catenaro}

\section{(2) OpenEdition}

1 Journals

\section{Edizione digitale}

URL: http://journals.openedition.org/studifrancesi/7735

DOI: $10.4000 /$ studifrancesi. 7735

ISSN: 2421-5856

\section{Editore}

Rosenberg \& Sellier

\section{Edizione cartacea}

Data di pubblicazione: 1 décembre 2009

Paginazione: 675

ISSN: 0039-2944

\section{Notizia bibliografica digitale}

Dina Catenaro Catenaro, "Anne Marie Miraglia, Les figures du père immigré dans le texte dit «beur»,

«Francofonia»», Studi Francesi [Online], 159 (LIII | III) | 2009, online dal 30 novembre 2015, consultato il 09 janvier 2021. URL: http://journals.openedition.org/studifrancesi/7735 ; DOI: https://doi.org/

10.4000/studifrancesi.7735

Questo documento è stato generato automaticamente il 9 janvier 2021.

\section{(c) (1)}

Studi Francesi è distribuita con Licenza Creative Commons Attribuzione - Non commerciale - Non opere derivate 4.0 Internazionale. 


\title{
Anne Marie Miraglia, Les figures du père immigré dans le texte dit «beur», «Francofonia»
}

\author{
Dina Catenaro Catenaro
}

\section{NOTIZIA}

ANNE MARIE MIRAGLIA, Les figures du père immigré dans le texte dit «beur», «Francofonia», autunno 2008, n. 55, pp. 21-32.

1 Attraverso un'attenta analisi che parte dalla tradizione del romanzo nord-africano, fino a soffermarsi nello specifico sulle opere scritte da romanziere/i nate/i in Francia da genitori maghrebini (quali Farida Belgoul, Tassadit Imache, Jeanne Benameur e Sonia Moumen), Anne Marie Miraglia affronta il tema della rappresentazione paterna all'interno del cosiddetto roman beur, mettendo in luce il problematico rapporto che gli stessi padri immigrati in Francia hanno con la propria eredità culturale e con la trasmissione di questa alle generazioni future. Quello che l'autrice evidenzia dalle prime pagine del saggio, è la difficoltà che il romanziere nord-africano ha dovuto da sempre affrontare nel voler scrivere del proprio padre, poiché l'atto stesso del parlarne è considerato irrispettoso all'interno della società musulmana, nella quale, come afferma la stessa Miraglia, «l'homme doit respect et obéissance à son père et il demeure un enfant tant que son père est en vie» (p. 21). Tuttavia le cose sembrano cambiare presso le scrittrici e gli scrittori «beurs» che si servono principalmente di testi a carattere autobiografico al fine di prendere la parola su storie individuali e collettive che vengono taciute dai loro padri, storie che rischiano di scomparire con la loro morte, storie spesso omesse perché ricordare è troppo doloroso e/o perché non si posseggono gli strumenti linguistici necessari per poter parlare del proprio vissuto. Tra i diversi romanzi citati da Anne Marie Miraglia possono assurgere ad esempi il récit di Leïla Sebbar, Je ne parle pas la langue de mon père (2003) e Le Marteau-pique-cœur (2004) di Azouz Begag, opere significative che l'autrice esamina per mostrare come la sete di 
conoscenza delle proprie origini da parte dei beurs venga spesso a scontrarsi con un atteggiamento ostinato, votato al silenzio e all'oblio da parte dei loro padri immigrati. Un altro elemento problematico evidenziato in queste opere è quello del matrimonio misto tra uomini appartenenti alla cultura araba e donne occidentali e della difficoltà che spesso l'uomo immigrato incontra nel dover esprimere in una lingua diversa dalla sua le proprie sofferenze, e soprattutto l'affermazione della propria differenza. Attraverso un'attenta lettura dell'opera di Leïla Sebbar, ad esempio, Anne Marie Miraglia evidenzia come la perdita del codice linguistico paterno porti in sé come grave conseguenza l'inaccessibilità dei figli ad un mondo di saperi ricco e variegato, e come lo stesso padre, con il proprio silenzio, si sia fatto complice di questa privazione. Anche il récit di Sonia Moumen, Mon père est un petit bicot (2005), pur mostrando un padre nordafricano che si è adattato alla cultura occidentale, che ha quasi dimenticato la lingua di origine e che si reca in Algeria soltanto dopo venticinque anni di assenza, sembra suggerire come tale integrazione abbia portato i figli ad ignorare la propria eredità ancestrale. Come la stessa Miraglia ci suggerisce, le narratrici protagoniste (bambine o donne molto giovani) sono in preda a sentimenti contrastanti e, come avviene alla voce narrante di Ça t'apprendra à vivre di Jeanne Benameur, vivono una grande lacerazione interna: sono persone à moitié (p. 25), che non riescono ad affermare la propria identità nella sua interezza. Spesso (è il caso della narratrice adulta di Une fille sans histoire di Tassadit Amache), tale duplicità si traduce in uno strappo lacerante tra la cultura occidentale, quella dei forti e dei privilegiati, rappresentata dalla madre francese, e la cultura degli oppressi, quella degli africani, rappresentata dal padre cabile. Le lotte per l'Indipendenza, come la guerra d'Algeria e i massacri perpetrati su un intero popolo, fanno da sfondo a interrogazioni più intime, alla propria storia individuale che tuttavia non può prescindere da quella collettiva.

2 Anne Marie Miraglia lo scrive a chiare lettere: «Si, pendant la guerre d' Indépendance, les enfants ont vengé leurs pères avilis et impuissants en prenant les armes, leurs propres enfants le font aujourd'hui en prenant la plume» (p. 31). E l'autrice ci mostra molto bene come la penna possa restituire la parola a quei padri dal silenzio impenetrabile. 